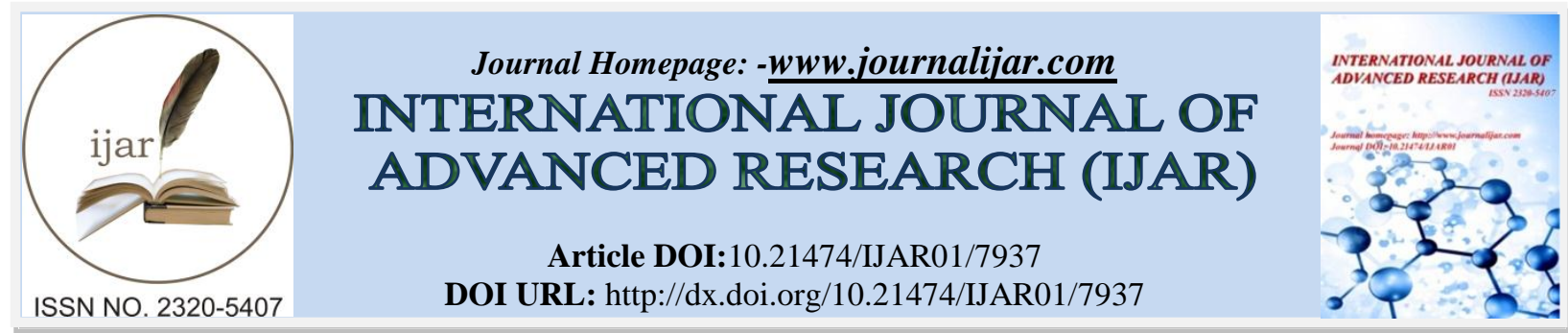

RESEARCH ARTICLE

\title{
INFLUENCE OPTICAL, STRUCTURAL AND EXTERNAL MORPHOLOGICAL PROPERTY OF FE SUBSTITUTED IN ZNO THIN FILMS.
}

\section{R. T. Ubale ${ }^{1}$ and S. B. Bajaj ${ }^{2}$.}

1. Department of Physics,Siddharth Arts, Commerce and Science College, Jafrabad, Jalna, (India).

2. Department of Physics, JES College, Jalna, Maharashtra, India.

\section{Manuscript Info}

Manuscript History

Received: 15 August 2018

Final Accepted: 17 September 2018

Published: October 2018

Keywords:-

$\mathrm{X}$ - Ray diffraction, $\mathrm{ZnO}, \mathrm{UV}=\mathrm{Vis}$,

Raman Spectroscopy, Band gap,

Crystallite size.

\begin{abstract}
Fe doped ZnOthin films with different Fe concentrations have been deposited by Sol-gel method. X-ray diffraction (XRD) confirmed that hexagonal wurtzite structure in all samples. However, the preferential orientation changed from (002) to (101) plane with increase of $\mathrm{Fe}$ doping. Unit cell parameters, ' $a$ ' and ' $c$ ', reduced with the enhancing the Fe content up to 5\%, which indicated that Fe ions substitute into the lattice of zno. The Raman spectroscopy measurement showed the peaks at $377.33 \mathrm{~cm}^{-1}, 439.14 \mathrm{~cm}^{-1}$ and $538.76 \mathrm{~cm}^{-1}$ which are the characteristic vibrational modes of zno. The scanning electron microscopic (SEM) images showed irregular shaped grains grown over the substrate surface for pure zno. After $\mathrm{Fe}$ doped zno thin films exhibits the spherical and hexagonal structure. UV-Vis spectra of show the decrement the band gap up to 3.18 to $2.92 \mathrm{eVafter}$ the enhancing the Fe concentration.
\end{abstract}

Copy Right, IJAR, 2018,. All rights reserved.

\section{Introduction:-}

$\mathrm{ZnO}$ is one of the most intentional materials of the II-VI oxide materials that originate continuous devotion of the researchers worldwide since forties (Bunn 1935). Since of its current and potential applications in several novel devices, renewed interest has emerged and several reviews. Some of the favorable aspects of $\mathrm{ZnO}$ include its radiation hardness, biocompatibility and its high transparency in visible region. $\mathrm{ZnO}$ is important for its multifunctional properties (optical, semiconducting, structural, magnetic, piezoelectric etc.) for electronic and optoelectronic devices. Among different physical forms, the thin films of $\mathrm{ZnO}$ find a multitude of immensely important applications in electronic and optoelectronic devices such as transparent conductors, solar cell windows, gas sensors, devices, heat mirrors etc. [1-5]. Freshly, $\mathrm{ZnO}$ based photocatalysts have been effectively used to convert organic pollutants in water into pollutant-free materials through UV light or simulation daylight [6-8]. However, the quantum efficiency of $\mathrm{ZnO}$ is rather low due to the fast recombination of photo induced hole-electron pairs.Transition Metals (TM) like $\mathrm{Fe}, \mathrm{Mn}$, Co and $\mathrm{Ni}$ doped $\mathrm{ZnO}$ have a scientific advantage for their promising magnetic, optical and electronic properties required for spintronic materials and optoelectronic devices [9-11]. Among these, $\mathrm{Fe}$ doping can considerably insist intrinsic ferromagnetism in diluted magnetic semiconductors e.g. $\mathrm{ZnO}[12-18]$.

Fe doped $\mathrm{ZnO}$ films are a subject of continuous study as their optical as well as structural and morphological properties may take a sudden turn depending heavily on the method of deposition. An increase of $18 \mathrm{meV}$ in optical band gap of Fe doped films prepared by sol-gel spin coating method was reported by Xu et al. [19]. Parra-Polomino

Corresponding Author:-R. T. Ubale.

Address:-Department of Physics, Siddharth Arts, Commerce and Science College, Jafrabad, Jalna, (India). 
et al. [20] also described an increase, of $340 \mathrm{meV}$, in optical band gap of iron doped nanocrystals prepared by chemical route. n-type semiconducting metal oxides can also be used for gas sensing as they were able to show variation in some electrical parameters, viz. resistance and capacitance of the film upon adsorption of gases. Also, metal oxides are stable at elevated temperatures in air [21-25].In this paper we have study Fe doping in to $\mathrm{ZnO}$ up to $5 \%$ and improve the optical properties of $\mathrm{ZnO}$ material. In fact, Fe ion can be easily substituted on the $\mathrm{Zn}$-site, resulting in two more free electrons to contribute to the electrical conduction. We have also study the structural property and morphological investigation of Fe doped $\mathrm{ZnO}$ thin films.

\section{Experimental Details}

All the reagents used in the present work for the chemical preparation were of analytical grade. For pure zno thin films, zinc acetate dehydrate $\left(\mathrm{Zn}\left(\mathrm{CH}_{3} \mathrm{COO}\right)_{2} \cdot 2 \mathrm{H}_{2} \mathrm{O}\right)$ was dissolved in a 2-methoxyethanol $\left(\left(\mathrm{CH}_{3}\right)_{2} \mathrm{CHOH}\right)$ with monoethanolamine (MEA: $\mathrm{H}_{2} \mathrm{NCH}_{2} \mathrm{CH}_{2} \mathrm{OH}$ ) which was used as a capping agent. The molar ratio of MEA to zinc acetate was kept to 1.0 and concentration of zinc acetate was $0.80 \mathrm{~mol} / \mathrm{l}$. The resultant solution was stirred at $70^{\circ} \mathrm{C}$ for 60 minute to produce a clear and homogeneous solution ready for coating. The coating was performed with recently prepared solution.The films on ultrasonically cleaned quartz substrates were prepared using spin-coating unit which was rotated at $3500 \mathrm{rpm}$ for $40 \mathrm{~s}$. The films were heated at temperature $300^{\circ} \mathrm{C}$ for $10 \mathrm{~min}$ in a furnace to evaporate the solvent and remove organic residuals. The spincoating to heating procedure was repeated 15 times. The films were then annealed in air at $400^{\circ} \mathrm{C}$ for three hour.For 3\% and 5\% Fe doped zno same procedure were used. Structural properties were studied using Bruker D8 Advance diffractometer in $\theta-2 \theta$ geometry $(\mathrm{Cu} \mathrm{K \alpha}$ radiation, $\lambda=1.5406 \AA$ ) at UGC DAE CSR, Indore, India. Optical transmittance (band gap also) and surface morphology were studied using UV-Vis-NIR spectrophotometer (V-550) from Ms JASCO and Digital Instrument Nanoscope III $\left(\mathrm{Si}_{3} \mathrm{~N}_{4}\right)$ in contact mode (force constant $=0.58 \mathrm{~N} / \mathrm{m}$ ), respectively at UGC DAE CSR, Indore, India. Surface morphology was obtained using SEM (Model-ZEISS) at UGC DAE CSR, Indore, India. Raman spectra of pure and Mn doped zno samples were recorded by using of Ar ion laser with $514.5 \mathrm{~nm}$ wavelength and $50 \mathrm{mw}$ power was employed as the excitation source at UGC DAE CSR, Indore, India.

\section{Results and discussion:- Structural property}

X-ray (XRD)diffraction patterns used to investigate the crystallographic structure of the as-synthesized samples. The unit cell of the crystal was found to be hexagonal wurtzite with the presence of dominant peaks at (100), (002), (101), (102), (110), (103) and (112) as shown inFigure 1. It is in good agreement with the standard JCPDS card no. 89-0510. Irrespective of doping concentration, all the films showed peaks similar to pure zno, which indicates that no structural deformation arisen in zno lattice upon Fe-doping. This confirms the effective substitutional replacement of $\mathrm{Fe}$ ions in $\mathrm{Zn}$ lattice sites in the zno matrix. T. Srinivasulu [55] reported that all have same intensity but in our case, it was observed that the increase in intensity accounted for the influence of ions on the scattering factors of the unit cell. Enhancement in the intensity also may be due to change in the electronic density in the crystallographic position and increase in peak intensity is an indication of the improvement of crystallinity of the samples. The lattice parameters were evaluated by using the appropriate formulae mentioned in relation given below as available in the literature on hexagonal crystal structure [26].

$\frac{1}{d^{2}}=\frac{4}{3} \frac{\left[h^{2}+h k+k^{2}\right]}{a^{2}}+\frac{l^{2}}{c^{2}}(1)$

Where $\lambda$ is wavelength of $X$ - rays (1.540 $\AA), \theta$ is diffraction angle and h, $k, 1$ are miller indices, ' $a$ ' and 'c' are the lattice parameter and $\mathrm{d}$ is the interplanar spacing. The values of lattice constants for 3 at $\% \mathrm{Fe}$ doped $\mathrm{ZnO}$ thin films decrease the lattice parameter as increasing Fe concentration. The decrement in the lattice parameters with dopant concentration in the crystal can be understood as a phase transition or actual incorporation of dopant into the unit cell of the host structure. From the evaluated values, it is clear that $\mathrm{ZnO}$ films doped with 5 at. \% Fe showed less variation in the lattice parameters with $\mathrm{a}=2.923 \AA \mathrm{c}=5.094 \AA$ compared to pure $\mathrm{ZnO}$ films that had $\mathrm{a}=2.951 \AA$, $\mathrm{c}$ $=5.111 \AA$. This change in lattice parameters might be due to the substitutional replacement of $\mathrm{Fe}^{3+}$ impurity ions in the place of $\mathrm{Zn}^{2+}$ ionic sites in $\mathrm{ZnO}$ matrix, which causes a small misfit because of different ionic radius of Fe ions compared to $\mathrm{Zn}$ ions.

The crystallite size of pure and $\mathrm{Fe}$ doped $\mathrm{ZnO}$ pristine and irradiated thin films was calculated using Debye Scherrer's formula. 
$\mathrm{D}=\frac{0.9 \lambda}{\beta \cos \theta}$

Where $\mathrm{D}$ is the crystallite size, $\lambda$ is the wavelength with cuk $_{\alpha}$ is the radiation $(1.5406 \AA), \beta$ is the full width at half maxima and $\theta$ is the Bragg's angle of diffraction. The evaluated D values varied in the range, $30-45 \mathrm{~nm}$. It is also observed that the crystallite size increased initially with the introduction of Fe into zno films, thereafter, it gets decreased with increase of doping concentration. A large crystallite size of $45 \mathrm{~nm}$ was obtained for Fe $=5$ at.\% doped zno film.

Table 1:-List of Lattice parameter, Crystallite size, X-ray Density, Surface to volume ratio (S/V) and Tc calculated by using XRD data.

\begin{tabular}{|c|c|c|c|c|c|c|}
\hline \multirow[t]{2}{*}{ Sample } & \multicolumn{2}{|c|}{ Lattice parameter } & \multirow{2}{*}{$\begin{array}{l}\text { Crystalline } \\
\text { size D (nm) }\end{array}$} & \multirow{2}{*}{$\begin{array}{c}\text { X-Ray Density } \\
\left(\mathrm{gm} / \mathrm{cm}^{3}\right)\end{array}$} & \multirow{2}{*}{$\begin{array}{l}\mathrm{S} / \mathrm{V} \\
\text { ratio }\end{array}$} & \multirow{2}{*}{$\begin{array}{c}\text { Texture } \\
\text { coefficient } \\
\text { (Tc) }\end{array}$} \\
\hline & $\mathbf{a}(\AA)$ & c $(\stackrel{\AA}{\mathbf{A}})$ & & & & \\
\hline Pure $\mathrm{ZnO}$ & 2.932 & 5.109 & $30 \pm 0.5$ & 5.659 & 0.0532 & 4.203 \\
\hline $3 \% \mathrm{Fe}$ doped $\mathrm{ZnO}$ & 2.939 & 5.105 & $36 \pm 0.5$ & 5.556 & 0.0503 & 3.250 \\
\hline $5 \%$ Fe doped $\mathrm{ZnO}$ & 2.923 & 5.094 & $45 \pm 0.5$ & 5.539 & 0.0452 & 2.652 \\
\hline
\end{tabular}

The Texture Coefficient calculated by equation 3 [27]

$\mathbf{T}=\frac{\frac{I(h k l)}{I 0(h k l)}}{\sum_{n} \frac{i(h k l)}{I 0(h k l)}} \times 100 \%$

Where (hkl) is the measured relative intensity of ideal orientation plane (hkl), $\mathrm{I}_{0}(\mathrm{hkl})$ is the standard intensity of the preferred orientation (hkl) taken from JCPDS data and $n$ is number of diffraction peak considered.It is observed that TC values were decreased with increasing the Fe content, attributed to the crystal reorientation influence. Further, it is found that the $\mathrm{ZnO}$ film with at $5 \%$ Fe-doping showed large crystallite size, low texture coefficient and high lattice defects than the otherpure $\mathrm{ZnO}$ films. Here, high texture coefficient of the samples indicate that large number ofcrystallites are oriented along the (002) orientation parallel to the substrate surface. Therefore, Fe-doping concentration of $5 \%$ waschosen to optimize $\mathrm{ZnO}$ layers for better structural characteristics [28].The $\mathrm{S} / \mathrm{V}$ ratio of pure and Fe doped ZnOsamples is decreases after doping of Fe concentration it is due to the enhancing the crystallite size.

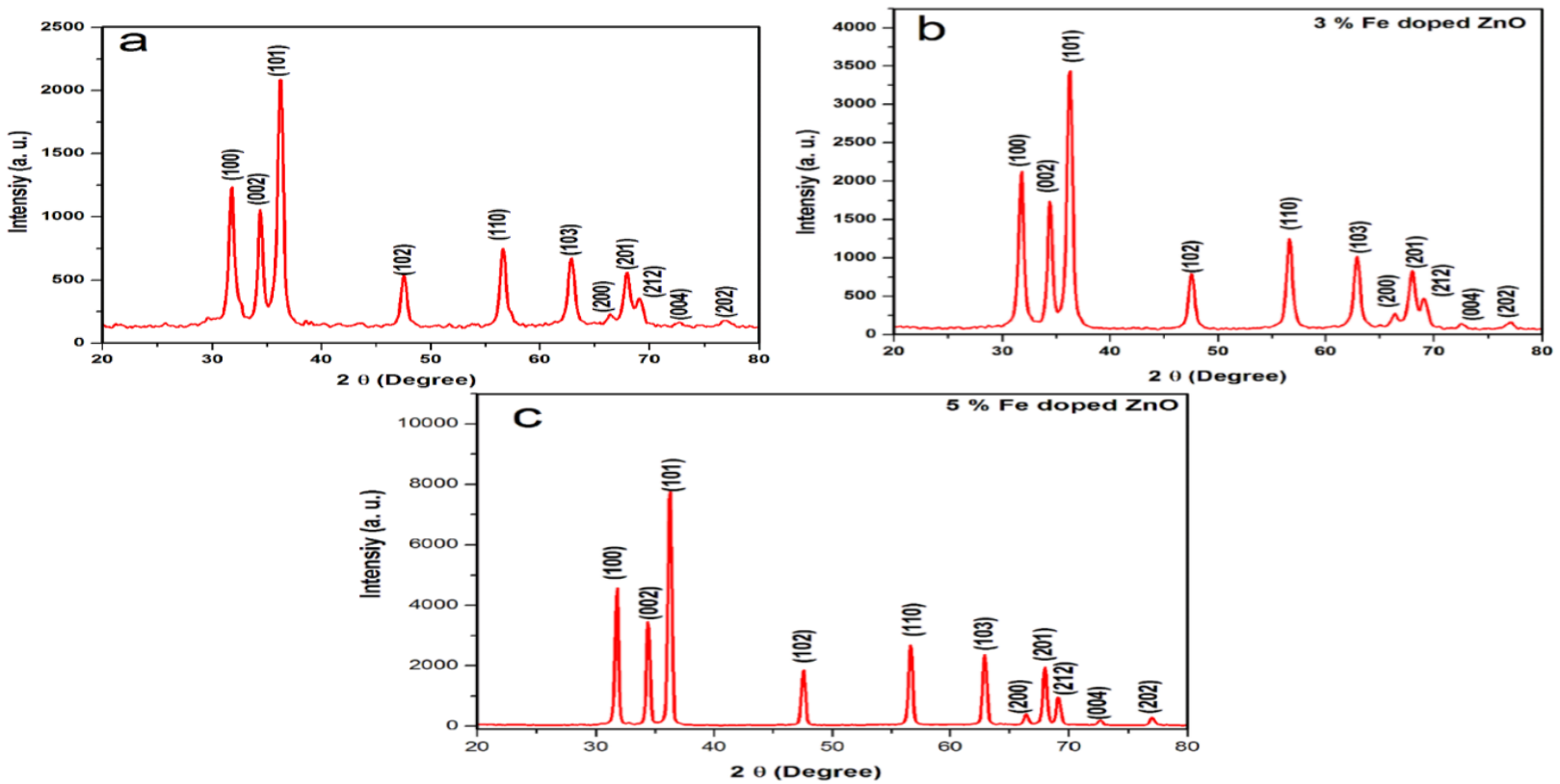

Figure 1:-a) Pure $\mathrm{ZnO}$ thin films b) $3 \%$ Fe doped $\mathrm{ZnO}$ c) $5 \%$ Fe doped $\mathrm{ZnO}$ thin films 


\section{Morphological study}

The morphology of Fe doped thin films were observed by SEM. Figure 2 shows the SEM micrographs of the pure and $\mathrm{Fe}$ doped ZnOfilms. In pure ZnOthe SEM results seemsthe spherical and agglomeration like morphology observed but after the 3 at\% doping of $\mathrm{Fe}$ ions its shows the large spherical and randomly oriented morphology was observed but after high doping of $\mathrm{i}$.e. 5\% of $\mathrm{Fe}$ in ZnOsamples exhibits the big grain and hexagonal like morphology. The average crystallite was calculated with the help of imageJsoftware. The average crystallite size of pure and Fe doped thin films obtained 23 to $46 \mathrm{~nm}$ it is well match with XRD result After the Fe doped the crystallite size was enhanced due to the effect of $\mathrm{Fe}$ ions goes on interstitial site in the $\mathrm{ZnO}$ atom.

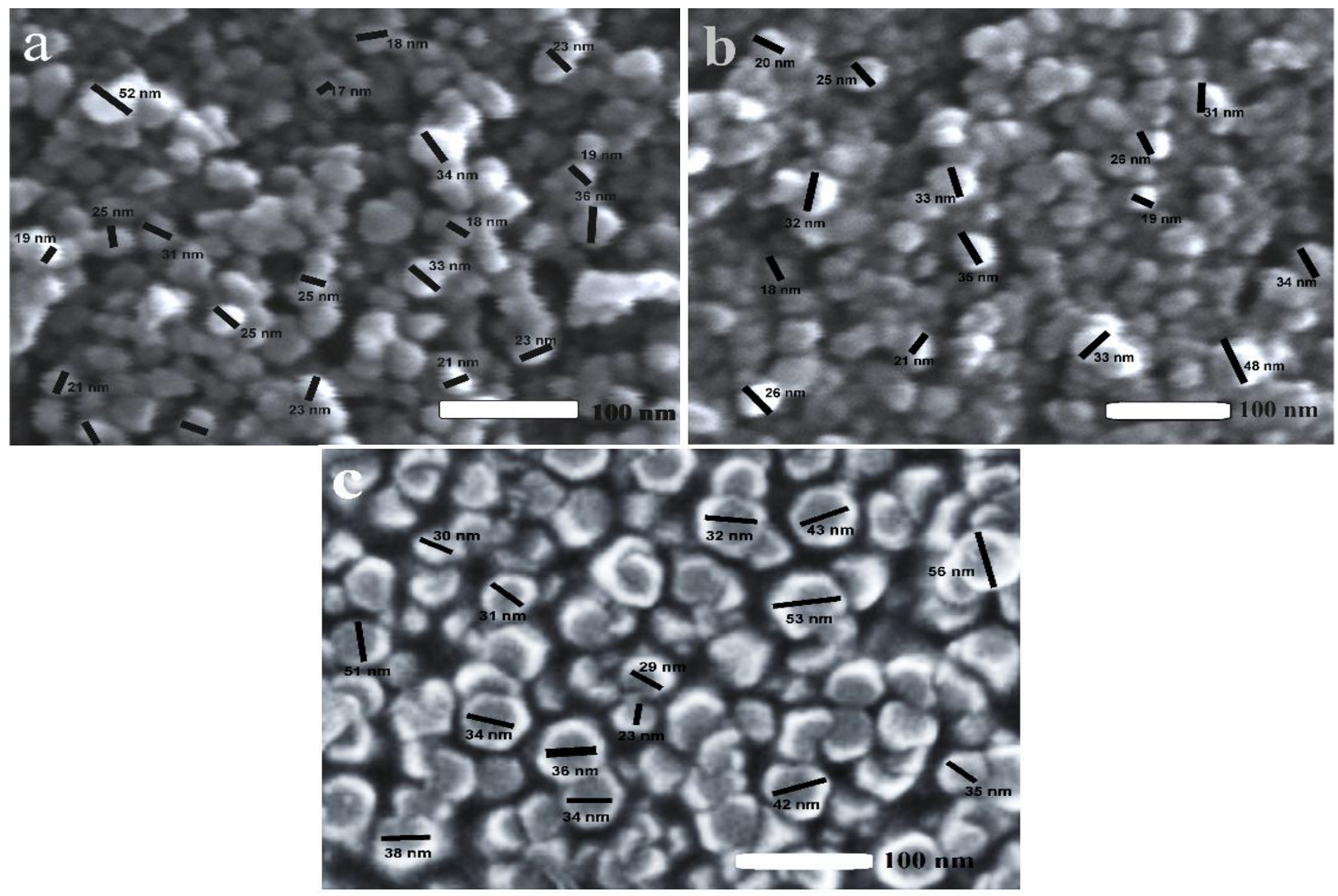

Figure 2:-(a) Pure $\mathrm{ZnO}$ thin film (b) $3 \%$ Fe doped $\mathrm{ZnO}$ thin film (c) $5 \%$ Fe doped $\mathrm{ZnO}$ thin film

\section{Raman study}

In figure 3 Shows the Raman spectra of Pure $\mathrm{ZnO}$ and $\mathrm{Fe}$ doped $\mathrm{ZnO}$ thin films. In pure $\mathrm{ZnO}$ the vibration modes observed at $333.53 \mathrm{~cm}^{-1}, 377.77 \mathrm{~cm}^{-1}, 574.98 \mathrm{~cm}^{-1}$, and $676.92 \mathrm{~cm}^{-1}$ it isoriginated due to the second order spectral feature obtained from thezone boundary phonons of $\mathrm{E}_{2}$ (high) and $\mathrm{E}_{2}$ (low). In $3 \% \mathrm{Fe}$ doped $\mathrm{ZnO}$ thin film the modes are observed at $333.53 \mathrm{~cm}^{-1}, 439.14 \mathrm{~cm}^{-1}, 575.53 \mathrm{~cm}^{-1}, 677.01 \mathrm{~cm}^{-1}$. The $439.14 \mathrm{~cm}^{-1}$ mode is commonly observed in Raman spectra of Fe-doped ZnOfilms and attributed to $\mathrm{E}_{2}$ (high) mode. The high-frequency $\mathrm{E}_{2}$ modeinvolves predominantly the movements of lighter oxygen atoms. Thevariation of $\mathrm{E}_{2}$ (high) in response to variation of $\mathrm{Fe}$ content in the films.

It is observed that as the concentration of $5 \% \mathrm{FeZnO}$ thin filmsthe phonon mode present at $439.14 \mathrm{~cm}^{-1}$ is shifted to higher wavenumber side, it is due tothe change in binding energy of $\mathrm{Zn}-\mathrm{O}$ bond as a result of replacing $\mathrm{Zn}^{2+}$ by $\mathrm{Fe}^{3+}$ and due to the induced strain, phonon confinement byboundaries and force constant changes that occurred by the incorporationof Fe-impurity into $\mathrm{ZnO}$ lattice. The enhancingthe intensity of $\mathrm{E}_{2}$ (high) mode with increase of $\mathrm{Fe}$ content in the films was attributed tothe change in lattice compression arisen due to the substitution ofFe ${ }^{3+}$ ions with smaller ionic radius $(0.64 \AA)$ in place of $\mathrm{Zn}^{2+}(0.74 \AA)$ in $\mathrm{ZnO}$ host. The broadening of the $\mathrm{E}_{2}$ peak with theincrease of Fe-doping shows that the oxygen vacancies, defects anddislocations were increased in the films. The vibrational mode presentat $538.76 \mathrm{~cm}^{-1}$ essentially corresponds to $\mathrm{E}_{1}$ (LO) (at $583 \mathrm{~cm}^{-1}$ ) and $\mathrm{A}_{1}$ (LO)(at $574 \mathrm{~cm}^{-1}$ ) Raman modes of $\mathrm{ZnO}$. The occurrence of these fundamentalRaman modes corresponds to the hexagonal wurtzite 
crystalphase of $\mathrm{ZnO}$. The additional vibrational mode present at $608.04 \mathrm{~cm}^{-1}$ isattributed to oxygen vacancies (VO), zinc interstitials (IZn), anti-siteoxygen etc. in $\mathrm{ZnO}$. The observed phonon modes are related to thewurtzite crystal structure of $\mathrm{ZnO}$ with a space group of $\mathrm{P}_{63} \mathrm{mc}(187)$.
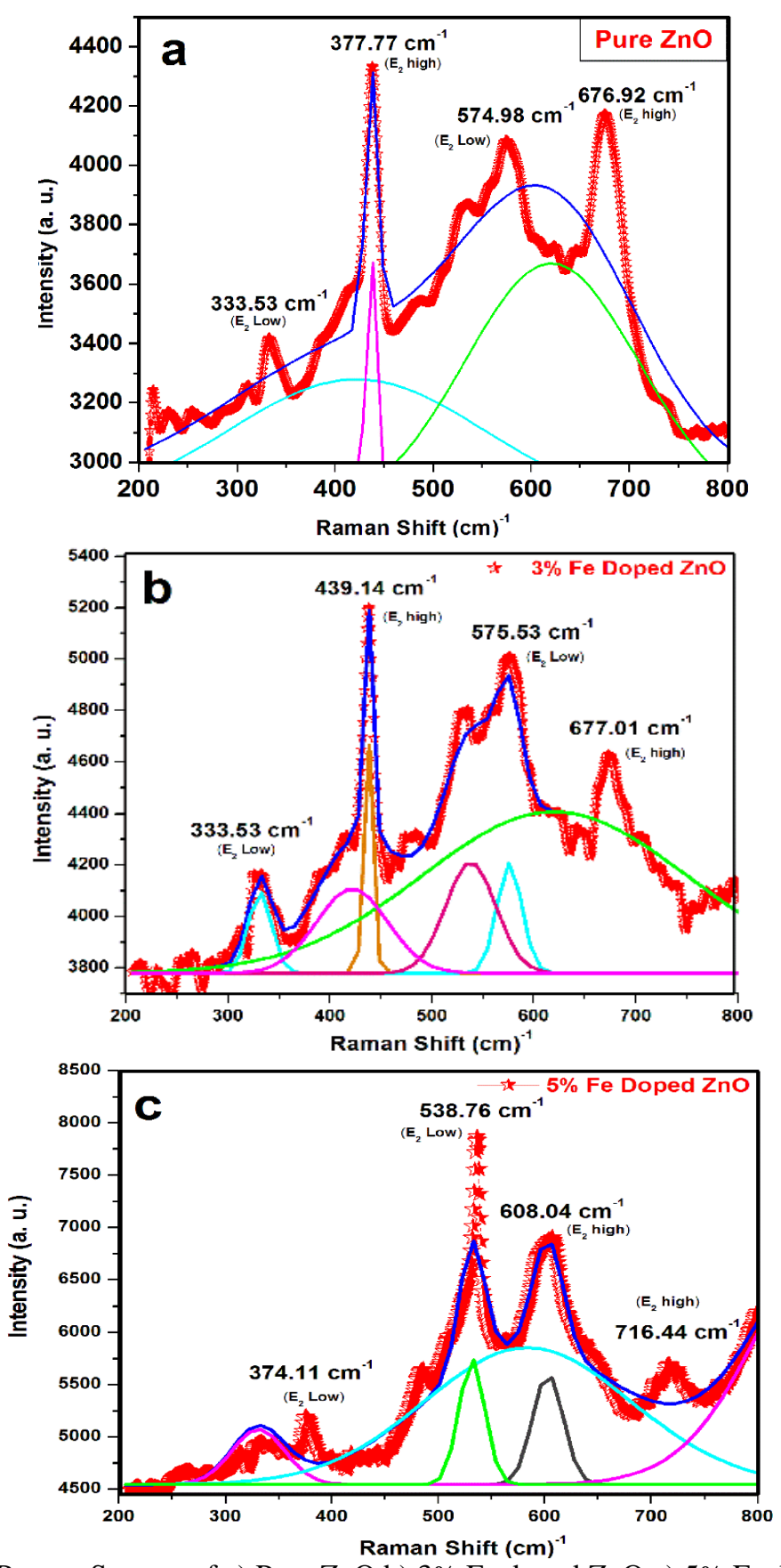

Figure 3:-Raman Spectra of a) Pure $\mathrm{ZnO}$ b) 3\% Fe doped $\mathrm{ZnO}$ c) 5\% Fe doped $\mathrm{ZnO}$.

\section{Optical Study}

UV-Visible absorption spectroscopy is extensively being used technique to examine the optical properties of nanosized particles. The absorption spectra are recorded in the range of $300-800 \mathrm{~nm}$ at room temperature as shown in figure 4. Absorption peaks are observed at 353.55, 354.64 and $359.62 \mathrm{~nm}$ are observed for pure $\mathrm{ZnO}, 3 \% \mathrm{Fe}$ doped $\mathrm{ZnO}$ and $5 \% \mathrm{Fe}$ doped $\mathrm{ZnO}$ thin films respectively, which lie below the standard band gap wavelength of bulk $\mathrm{ZnO}$ thin film is $358 \mathrm{~nm}(E g=3.47 \mathrm{eV})$. It clearly reflects that the exciton absorption peaks are shifted towards 
the higher wavelengths as increasing the Fe content. The energy band gap of pure and $\mathrm{Fe}$ doped $\mathrm{ZnO}$ samples was calculated considering absorption coefficient $(\alpha)$, which depends on the film thickness and absorbance by equation [29].

$\alpha=2.303\left(\frac{A}{d}\right)$

Where $A$ is the absorbance, and $d$ is the thickness. The energy gap was estimated by assuming a direct and indirect allowed transition between valence and conduction bands using the Tauc equation [30-31].

$\alpha h v=B\left(h v-E_{g}\right)^{1 / 2}$

Where $\mathrm{B}$ is the constant and $\mathrm{E}_{\mathrm{g}}$ is the energy band gap of the material. The plots of $(\alpha \mathrm{h} v)^{2}$ versus hv. The energy band gap of the pure $\mathrm{ZnO}$ sample was calculated $3.18 \mathrm{eV}$, but, after enhancing the $3 \%$ of Fe content, it was found to that $3.081 \mathrm{eV}$. It is confirmed that the band gap wasreduced due to the formation ofvacancies of oxygen in the sample. For 5\% Fe doped $\mathrm{ZnO}$ sample it was $2.92 \mathrm{eV}$. The reduced band gap of pure and 3\%, 5\% Fe doped $\mathrm{ZnO}$ as compared to the pure $\mathrm{ZnO}$ thin films. It also may be due to the substitution of $\mathrm{Fe}$ ion intoZnO lattice and hence affecting the sp-d interaction between the d-electrons of $\mathrm{Fe}$ ions and bandelectrons of $\mathrm{ZnO}$ in its tetrahedral crystal field and the clustering. This property may be applicable inseveral optoelectronic devices and reaching improve photocatalytic efficiency.

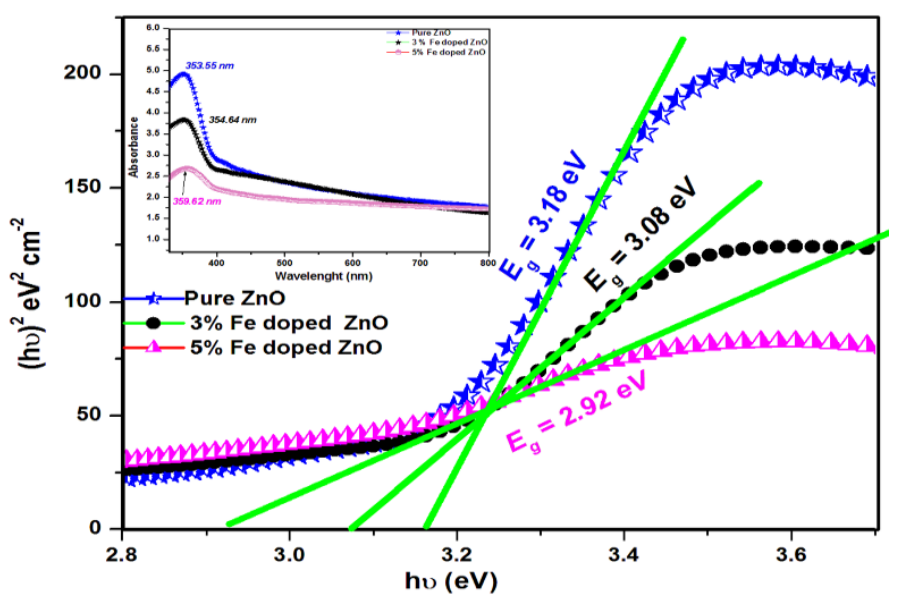

Figure 4:-UV-Vis spectra Tauc's plot(inset absorbance spectra) of pure and3\%, 5\% Fe doped ZnO thin films.

\section{Conclusion:-}

Fe doped $\mathrm{ZnO}$ thin films with various Fe doping concentrations have been successfully deposited by Sol-gel technique on glass substrates. XRD spectra reveals that hexagonal wurtzite structure in all samples, Unit cell parameters, a and c, decreases with the increasing the Fe content up to 5\%, which specified that Fe ions substitute into the lattice of $\mathrm{ZnO}$. The Raman spectroscopy measurement exhibited the peaks at $377.33 \mathrm{~cm}^{-1}, 439.14 \mathrm{~cm}^{-1}$ and $538.76 \mathrm{~cm}^{-1}$ which are the belongsto vibrational modes of $\mathrm{ZnO}$. The scanning electron microscopic (SEM) images showed irregular shaped grains grown over the substrate surface for pure $\mathrm{ZnO}$. After Fe doped $\mathrm{ZnO}$ thin films exhibits the spherical and hexagonal structure. UV-Vis spectra of show the decrement the band gap up to 3.18 to $2.92 \mathrm{eV}$ after the enhancing the Fe concentration. 


\section{References:-}

1. L. Lei, B. D., Sosnowchik, L. Lin, Appl. Phys. Lett. 90 (2007) 093101.

2. D. Wu, Z. Huang, G. Yin, Y. Yao, X. Liao, D. Han, X. Huang, J. Gu, CrystEngComm, 12 (2010) 192-198.

3. V. Bhosle, J.T. Prater, F. Yang, D. Burk, S.R. Forrest, J. Narayan, J. Appl. Phys. 102 (2007) 023501.

4. M. Abdeen, O. M. Hemeda, E. E. Assem, M. M. El-Sehly, J. Magn. Magn. Mater, 238 (2002) 75.

5. S. Rehman, R. G. Singh, J. C. Pivin, W. Bari, F. Singh, Vaccum, 86 ( 2011) 87-90.

6. D. Thomas, T. Thomas, J. Prakash, P. A. Tomlal, E. Jose, and S. Augustine, Int. J. Electrochem. Sci., 10 (2015) $7771-7782$.

7. K. Ando, H. Saito, Z. Jin, T. Fukumura, M. Kawasaki, Y. Matsumoto and H. Koinuma, J. Appl. Phys., (2001) 89, 7284-7286.

8. L.M. Wang, Jyh-Wei Liao, Zi-An Peng, Jian-Hong Lai, J. Electrochem. Soc. 156 (2009) H138.

9. H. Ohno, Science, (1998) 281, 951-955.

10. H. Liu, J. Yang, Y. Zhang, L. Yang, M. Wei and X. Ding, J. Phys.: Condens. Matter, 2009, 21, 145803.

11. J. H. Park, M. G. Kim, H. M. Jang and S. Ryu, Appl. Phys. Lett., 2004, 84, 1338-1340.

12. D. Wang, Z. Q. Chen, D. D. Wang, J. Gong, C. Y. Cao, Z. Tang and L. R. Huang, J. Magn. Magn. Mater., 2010, $322,3642-3647$.

13. X. Z. Li, J. Zhang and D. J. Sellmyer, Solid State Commun., 2007, 141, 398-401.

14. AbdelAal, Sawsan A. Mahmoud, Ahmed K. Aboul-Gheit, Nanoscale Res. Lett. 4(2009)627.

15. Wang, Z. Chen, Y. He, L. Li, Dong Zhang, Appl. Surf. Sci. 255 (2009) 6881.

16. A. K. Yadav, S. M. Haque, D. Shukla, R. J. Choudhary, S. N. Jha and D. Bhattacharyya, AIP Adv., 5 (2015) 5, 117138.

17. J. George, Preparation of Thin Films, Marcel Dekker, NY, 1992.

18. J. Chen, X. M. Wu, Z. D. Sha, L. J. Zhuge and Y. D. Meng, J. Phys. D: Appl. Phys., 39 (2006) $4762-4765$.

19. L. XU, X. LI, J. Cryst. Growth, 312 (2010), 851.

20. P.Palomino, Perales-Perez O., Singhal R., Tomar M., Hwang J., Voyles P.M., J. Appl. Phys., 103 (2008), 07121.

21. S. Dixit, A. Srivastava, A. Srivastava, R. K. Shukla, J. Appl. Phys., 102 (2007), 113114.

22. R. D. Shannon, Acta Crystallogr, 32(1976) 751-767.

23. E. H. Kisi and M. M. Elcombe, Acta Crystallogr, 45 (1989) 1867-1870.

24. A.Yavuz Oral, Z.Banu Bahsi,M.Hasan Aslan,Appl.Surf.Sci.253(2007)4593.

25. D. P. Joseph, C. Venkateswaran, J. Atomic Molec. Opt. Phys. (2011) 270540.

26. F.K. Shan, B.I. Kim, G.X. Liu, Z.F. Liu, J.Y. Sohn, and W.J. Lee, B.C. Shin, and Y. S. Yu, J. Appl. Phys. 95 (2004) 4772.

27. T. Srinivasulu, K. Saritha, K.T. Ramakrishna Reddy., Modern Electronic Materials 3 (2017) 76-85

28. S. Ilican, M. Caglar, Y. Caglar, Mater. Sci.- Pol. 25 (2007) 709-718.

29. H. Kumar and R. Rani, ILCPA, 19 (2013)19, 26-36.

30. W. R. Saleh, N. M. Saeed, W. A. Twej and M. Alwan, AMPC, 02(2012), 11-16.

31. S. Kuriakose, D. Avasthi and S. Mohapatra, Bseilstein J. Nanotechnol., 06 (2015) 928-937. 